\title{
An Analysis of Tropical Cold-Point Tropopause Warming in 1999
}

\author{
Yuanyuan Han, ${ }^{1}$ Fei Xie, ${ }^{2}$ Shiyan Zhang, ${ }^{1}$ Ruhua Zhang, \\ Feiyang Wang, ${ }^{1}$ and Jiankai Zhang ${ }^{1}$ \\ ${ }^{1}$ Key Laboratory for Semi-Arid Climate Change of the Ministry of Education, College of Atmospheric Sciences, \\ Lanzhou University, Lanzhou, China \\ ${ }^{2}$ State Key Laboratory of Earth Surface Processes and Resource Ecology and College of Global Change and Earth System Science, \\ Beijing Normal University, Beijing, China
}

Correspondence should be addressed to Fei Xie; xiefei@bnu.edu.cn

Received 24 December 2016; Accepted 1 March 2017; Published 26 March 2017

Academic Editor: Dong Guo

Copyright (C) 2017 Yuanyuan Han et al. This is an open access article distributed under the Creative Commons Attribution License, which permits unrestricted use, distribution, and reproduction in any medium, provided the original work is properly cited.

\begin{abstract}
Using reanalysis datasets, the warming of the tropical tropopause in 1999 and its evolution are investigated. It is found that there is a strong rate of increase in tropical cold-point tropopause temperature (CPTT) in June 1999, with negative CPTT anomalies before June (March-April-May) and large positive anomalies after June (July-August-September). Multiple linear regression analysis shows that deep convection, the quasi-biennial oscillation (QBO), and tropical upwelling associated with the Brewer-Dobson circulation (BDC) largely explain the variations of CPTT in 1999. Before June, enhanced deep convection resulting from increased sea surface temperature (SST) over the western Pacific and enhanced tropical upwelling of the BDC lead to a higher and colder tropopause. Those two factors explain $22 \%$ and $17 \%$ of the variance in CPTT, respectively. In June, the transformation of the east phase of QBO to the west phase contributes up to more than $50 \%$ of the variance in CPTT changes. After June, reduced tropical upwelling induced by weakened wave activity results in the warmer tropical tropopause temperatures to a large extent.
\end{abstract}

\section{Introduction}

Stratospheric processes can influence tropospheric weather and climate system not only through the dynamical processes [1-5] but also via the radiative effects of the greenhouse gases in the stratosphere $[6,7]$. As one of the most important greenhouse gases in the stratosphere, water vapor plays a crucial role in the atmospheric radiation budget and chemical processes $[8,9]$. The tropical tropopause temperature is the main factor controlling stratosphere water vapor variations [10-15]. That is, when air enters the stratosphere from the troposphere in the tropics, cold tropical tropopause would result in very low water vapor mixing ratios throughout the stratosphere by effective freeze-drying of the air [16, 17]. Dessler et al. $[9,18]$ demonstrated a close connection between interannual variations in tropical tropopause temperatures and stratospheric water vapor. A sudden decrease in the stratospheric water vapor after 2001 is attributed to the reduced tropical tropopause temperature [19]. Tian and
Chipperfield [20] pointed out that a trend of $+0.44 \mathrm{~K} /$ decade in tropical tropopause temperature can account for $70 \%$ of the modeled lower stratosphere water vapor trend. In addition, Rosenlof and Reid [12] showed that each degree of the tropical tropopause temperature cooling would lead to an approximately $15 \%$ decrease in saturated water vapor mixing ratios in the lower stratosphere. In addition to the importance of tropical tropopause temperature for stratospheric water vapor, changes in global atmospheric circulation associated with atmospheric angular momentum and the formation of tropical thin cirrus clouds are also strongly influenced by the tropical tropopause temperature [21-23].

The above analysis illustrates thatthe tropical tropopause temperature is significantly sensitive to climate variability and climate change, and therefore it has drawn a great deal of attention over the past decades [24-26]. Several studies have shown that changes in tropical tropopause temperature are the result of combined effects. Based on reanalyses of European Center for Medium-Range Weather Forecast 
(ECMWF), Zhou et al. [27] analyzed the variability in the tropical cold-point tropopause temperature (CPTT) before 2000 using an empirical orthogonal function (EOF) analysis and showed that the leading modes of CPTT variability are associated with the quasi-biennial oscillation (QBO) and El Niño-Southern Oscillation (ENSO). Several studies have also confirmed that QBO and ENSO are the primary drivers of variations in tropical tropopause temperature from 1950 to 1980 [28-30]. Further observational evidence on ENSO or QBO-related CPTT changes are documented using the latest observational datasets [31, 32]. Apart from the effects of the QBO and ENSO, strong tropical convection can reach up to the tropopause and further lead to variations in the tropical cold-point tropopause height $(\mathrm{CPTH})$ and CPTT $[33,34]$. Zhou et al. [35] suggested that changes in tropical deep convection explain the cooling trend in the CPTT for the period of 1973-1998. Subsequently, Rosenlof and Reid [12] confirmed that cooling of the tropical lower stratosphere is likely due to tropospheric convection to a large extent. Xie et al. [36] found that the leading principal component (PC1) of CPTT variability since the 1980s is associated with the tropical CPTH. They further pointed out that QBO and ENSO are two additional factors that account for CPTT variability. Moreover, the upwelling of large-scale BrewerDobson circulation (BDC) in the stratosphere also can influence the temperature and compositions of the tropopause layer [37].

Except for their long-term trend and interannual variability [28, 35, 38-40], tropical tropopause temperature sometimes shows extreme warming or cooling in a year; for example, Randel et al. [19] found an abrupt decrease in tropical tropopause temperature (approximately $-1 \mathrm{~K}$ ) in 2001, leading to a sudden decrease of stratospheric water vapor during the same period. On the other side, the case associated with strong warming of the tropical tropopause deserves to be analyzed. In this study, we primarily focus on investigating the sudden warming of the tropical tropopause in 1999 and relevant factors or processes which influence the warming. The paper is organized as follows: Section 2 gives a description of the data and methods used in the study; the warming in 1999 and its relevant impact factors are analyzed in Sections 3 and 4. Conclusions are given in Section 5.

\section{Data and Methods}

The tropical CPTT is defined in this study as the position where the temperature is coldest in the temperature profile. The tropics extend from $20^{\circ} \mathrm{N}$ to $20^{\circ} \mathrm{S}$. Zonal wind shear between $10^{\circ} \mathrm{N}$ and $10^{\circ} \mathrm{S}$ at $70 \mathrm{hPa}$, which is close to the tropopause, is used as an index for the stratospheric QBO [41].

To diagnose the effect of the BDC on the sudden warming, the vertical velocity of the BDC is calculated in this study [42].

$$
\bar{w}^{*}=\bar{w}+\frac{1}{r_{0} \cos \phi} \frac{\partial}{\partial \phi}\left(\frac{v^{\prime} \theta^{\prime} \cos \phi}{\overline{\theta_{p}}}\right),
$$

where $r_{0}$ is Earth's radius, $\theta$ is potential temperature, $\phi$ is latitude, and $w$ and $v$ are the vertical and meridional velocity, respectively.

The effective number $\left(N^{\text {eff }}\right)$ of degrees of freedom (DOF) [43] is used in this study, which can be determined by the following approximation [44]:

$$
\frac{1}{N^{\mathrm{eff}}} \approx \frac{1}{N}+\frac{2}{N} \sum_{j=1}^{N} \frac{N-j}{N} \rho_{X X}(j) \rho_{Y Y}(j),
$$

where $N$ is the sample size and $\rho_{X X}$ and $\rho_{Y Y}$ are the autocorrelations of two sampled time series, $X$ and $Y$, at time lag $j$, respectively.

The daily meteorological fields used in this study are obtained from the European Center for Medium-Range Weather Forecast Interim (ERA-Interim) reanalysis data for the time period between 1994 and 2005 (because we only investigate the tropopause temperature warming in 1999, the use of data extending from 1994 to 2005 is sufficient for this study and to calculate a climatology representative of the 2000s). ERA-Interim reanalysis data assimilates new model outputs and satellite observations and provides data at a horizontal resolution of $1.5^{\circ}$ latitude $\times 1.5^{\circ}$ longitude on 37 vertical layers from 1000 to $1 \mathrm{hPa}[45,46]$. More details about ERA-Interim reanalysis data can be found in Dee et al. [47]. The Modern-Era Retrospective Analysis for Research and Applications (MERRA) reanalysis dataset with a horizontal resolution of $1.25^{\circ}$ latitude $\times 1.25^{\circ}$ longitude and GOZCARDS (Global Ozone Chemistry and Related Trace Gas Data Records for the Stratosphere) satellite observations are also employed for a comparison. Data on outgoing longwave radiation (OLR) and Niño 3.4 index can be downloaded from https://www.esrl.noaa.gov/psd/data/gridded/data.interp_OLR .html and https://www.esrl.noaa.gov/psd/gcos_wgsp/Timeseries/Data/nino34.long.anom.data, respectively.

In this study, the daily variations of a variable in 1999 are calculated as the daily values minus those of daily mean values for the period of 1994-2005.

\section{The Strong Warming in the Tropical CPTT in 1999 and Its Associated Impact Factors}

Figure 1(a) shows time series of CPTT for the period of 1994-2005 derived from the ERA-Interim, MERRA, and GOZCARDS datasets. The CPTT from ERA-Interim is consistent with that from the other two reanalyses. A noticeable feature of Figure 1(a) is the relatively large increase in CPTT in 1999 and this phenomenon is also reflected in the other two datasets. Note that the positive CPTT anomalies in 1999 are strongest during the period of 1994-2005. Figure 1(b) further shows the temporal evolution of daily tropical CPTT in 1999 and the daily CPTT climatology in the 2000s. Clear evidence of a large rate of increase in CPTT anomalies is found in June and the CPTT anomaly reaches its maximum until July and the anomaly persists to September. It is interesting that negative CPTT anomalies are found in March, April, and May. To further investigate the increase in CPTT, June of 1999 is labeled as the period of "warming," March, April, and 


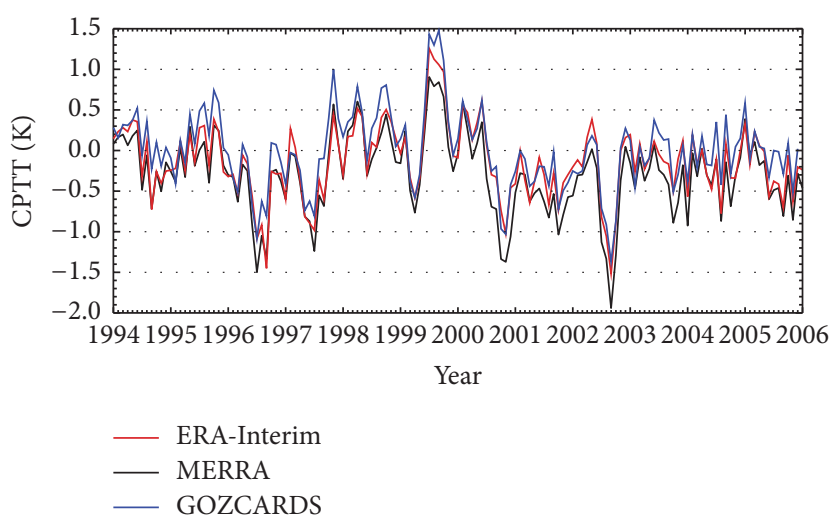

(a)

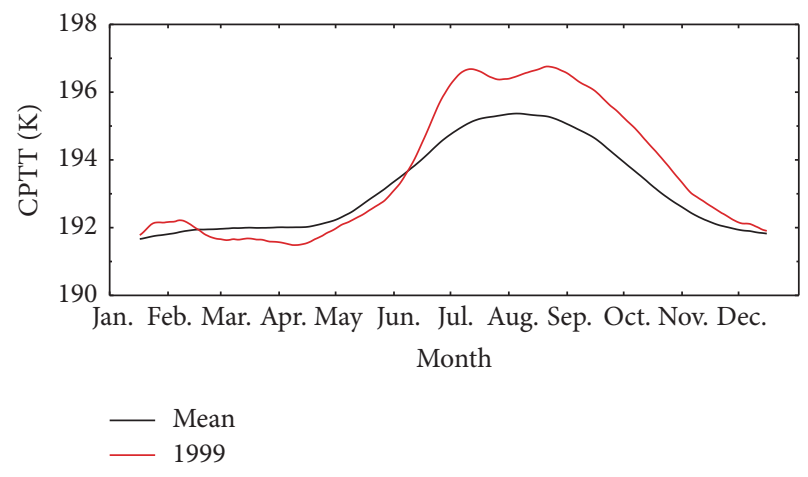

(b)

FIgURE 1: (a) Monthly time series of tropical mean $\left(20^{\circ} \mathrm{N}-20^{\circ} \mathrm{S}\right)$ CPTT for the period of $1994-2005$ derived from ERA-Interim (red line), MERRA (black line), and GOZCARDS (blue line) datasets. (b) Daily tropical CPTT variations in 1999 (red line) and CPTT climatology for the period from 1994 to 2005 (black line).

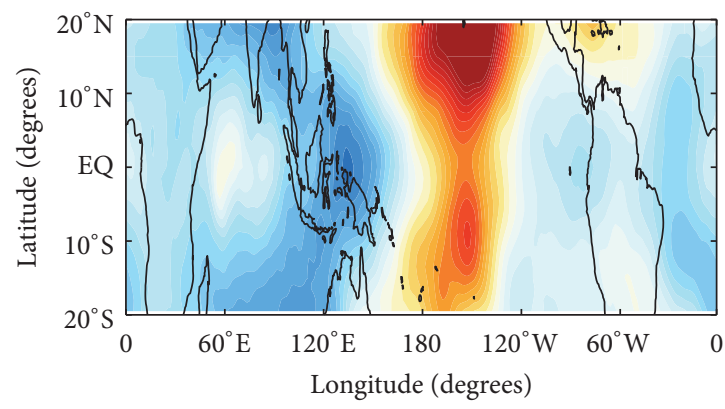

(a)
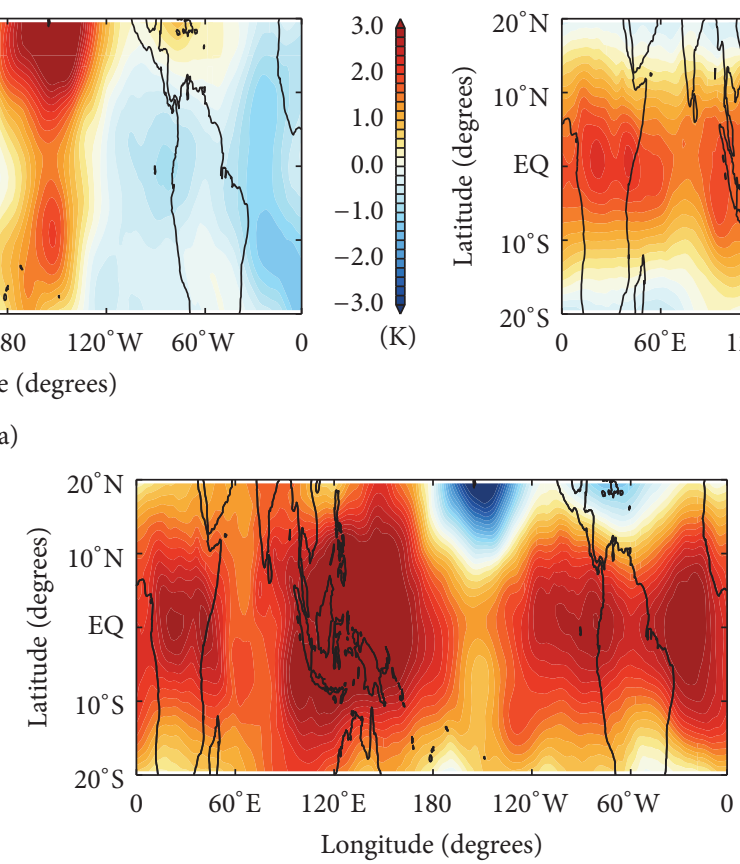

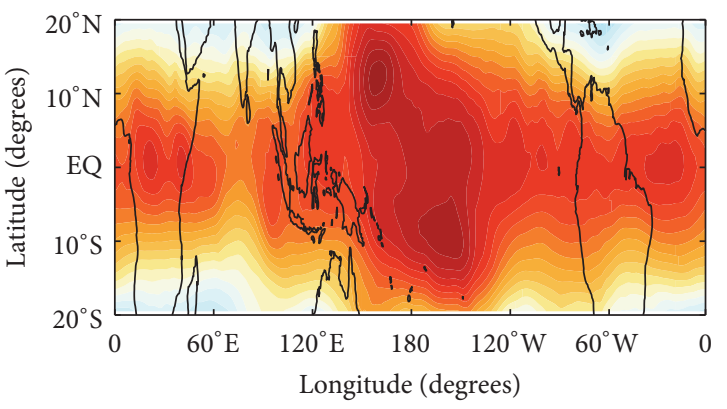

(b)

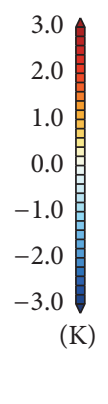

K)

(c)

FIgURE 2: The spatial distributions of CPTT anomalies during the (a) "prewarming" and (b) "postwarming" periods in 1999. CPTT anomalies are calculated by subtracting the CPTT daily climatology based on the period from 1994 to 2005 from the daily CPTT values in 1999 . (c) CPTT differences between the "postwarming" and "prewarming" periods.

May make up the "prewarming" period, and July, August, and September represent the "postwarming" period.

Figures 2(a) and 2(b) show the spatial distribution of CPTT during the "prewarming and postwarming" periods. During the "prewarming" period, the tropical CPTT exhibits positive anomalies over central Pacific Ocean and negative anomalies over the western Pacific Ocean with a minimum of approximately $-2.30 \mathrm{~K}$. The large negative anomalies cause the tropical mean CPTT in March, April, and May to be lower than the climatological CPTT values in the 2000s (Figure 1(b)). During the "postwarming" period, positive CPTT anomalies appear over the entire extent of the tropical oceans. The largest positive CPTT anomalies are located over the central Pacific Ocean and have values of approximately $3.12 \mathrm{~K}$. Figure 2(c) shows the difference of CPTT between the "postwarming" and "prewarming" periods. It can be seen that 


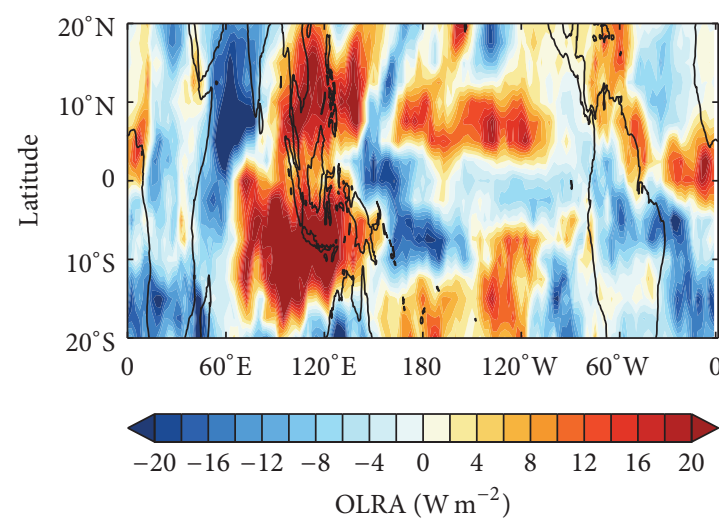

(a)

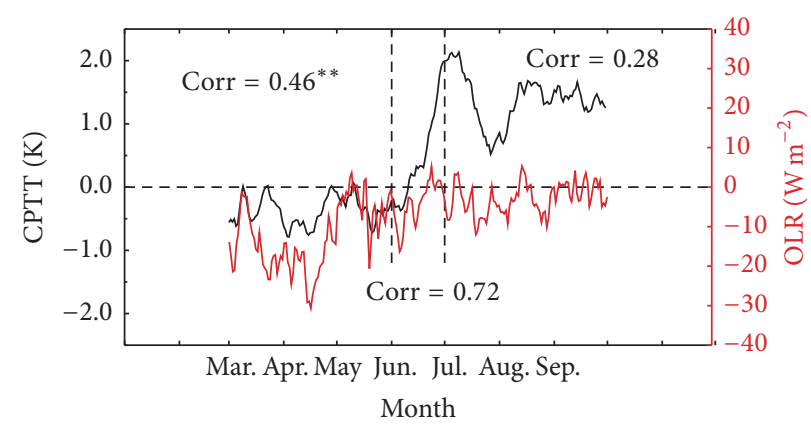

(b)

Figure 3: (a) Same as Figure 2(c) but for OLR. (b) Daily time series of CPTT (black line) and tropical eastern Indian Ocean and western Pacific Ocean averaged OLR (red line) in 1999. "Corr" represents the correlation coefficient between CPTT and OLR during the "prewarming," "warming," and "postwarming" periods. "**” indicates correlation coefficients that are significant at the $95 \%$ confidence level.

there are evident positive anomalies over the entire tropical oceans, further indicating that CPTT is larger during the "postwarming" period than during the "prewarming" period.

As mentioned in Introduction, tropical deep convection, the QBO, ENSO, and the BDC all have an impact on changes in the tropical tropopause temperature [31, 32, 48, 49]. In general, deep convection can lift up the tropopause and cause reduced tropopause temperature via adiabatic cooling processes $[29,36,50]$. Thus, we first analyze the CPTT variations related to deep convection. Figure 3(a) shows the differences in OLR during the "postwarming" period relative to the "prewarming" period. Note that OLR has been shown to be a good indicator of deep convection in the tropics [27]. It can be seen that there is an evident region of positive anomalies over the tropical eastern Indian Ocean and the western Pacific Ocean. This indicates that deep convection over the eastern Indian Ocean and western Pacific Ocean is stronger during the "prewarming" period than during the "postwarming" period. Figure 3(b) displays time series of daily OLR averaged over the tropical eastern Indian Ocean and the western Pacific Ocean and tropical CPTT during all three periods ("prewarming," "warming," and "postwarming"). Evident negative OLR anomalies appear during all three periods, indicating enhanced deep convection. During the "prewarming" period, the intensity of deep convection is stronger than those of the other two periods. Significant correlation coefficients during the "prewarming" period imply that enhanced deep convection is associated with colder tropopause temperature.

Figures 4(a)-4(d) further show longitude-pressure cross sections of vertical velocity anomalies and meridional distributions of OLR changes during the "prewarming and postwarming" periods. The positive (negative) vertical velocity anomalies exactly correspond to the negative (positive) OLR anomalies. That is, during the "prewarming" period, there are large positive vertical velocity anomalies in the upper troposphere over the tropical eastern Indian Ocean and the western Pacific Ocean, and the positive anomalies can extend to the lower stratosphere (Figure 4(a)). This corresponds to the large negative OLR anomalies (Figure 4(b)) which are associated with enhanced deep convection and a higher and colder tropopause. During the "postwarming" period, relatively small positive vertical velocity anomalies, accompanied by negative vertical velocity anomalies, exist over the tropical eastern Indian Ocean and the western Pacific Ocean. However, the vertical velocity anomalies only reach $150 \mathrm{hPa}$ (Figure $4(\mathrm{c})$ ). This corresponds to the relatively small OLR values (Figure 4(d)), which are associated with depressed deep convection and a lower and warmer tropopause. From the differences of vertical velocity and OLR anomalies between the "prewarming" and "postwarming" periods (Figures 4(e) and 4(f)), large positive anomalies exist over the tropical eastern Indian Ocean and the western Pacific Ocean, indicating that deep convection is stronger during the "prewarming" period compared to that during the "postwarming" period. A question naturally arises here as to which processes are mainly responsible for the differences in deep convection seen during the "prewarming and postwarming" periods.

Previous study has shown that there are close correlations between sea surface temperature (SST) and deep convection [51]. Figures 5(a) and 5(b) show the spatial distribution of SST during the "prewarming and postwarming" periods. Due to the occurrence of a La Niña event in 1999, the spatial pattern of SST anomalies is characterized by apparent positive anomalies and a stationary wave pattern known as the Matsuno-Gill pattern over the eastern Indian Ocean and western Pacific Ocean [52, 53]. Notably, SST is higher during the "prewarming" period than during the "postwarming" period over the tropical western Pacific Ocean and, particularly, over the northwestern Pacific Ocean. This feature can be clearly seen in the difference plot of SST between these two periods (Figure 5(c)). Zhang [51] pointed out that the frequency and strength of deep convection substantially increase with changes in SST from $26.5^{\circ} \mathrm{C}$ up to approximately $29.5 \sim 30^{\circ} \mathrm{C}$. Subsequently, Lau et al. [54] further 


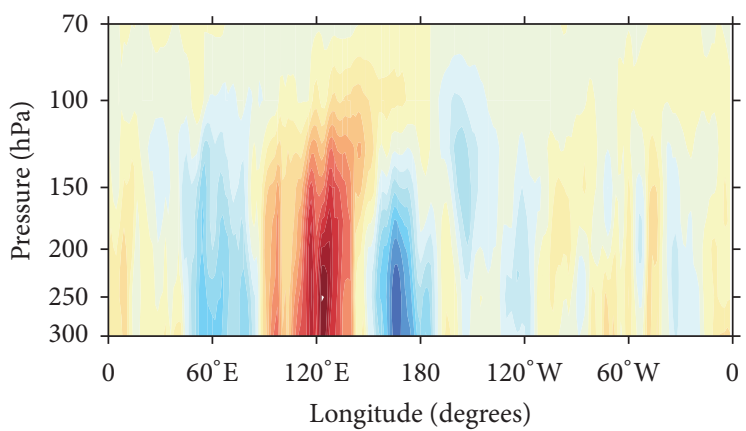

(a)

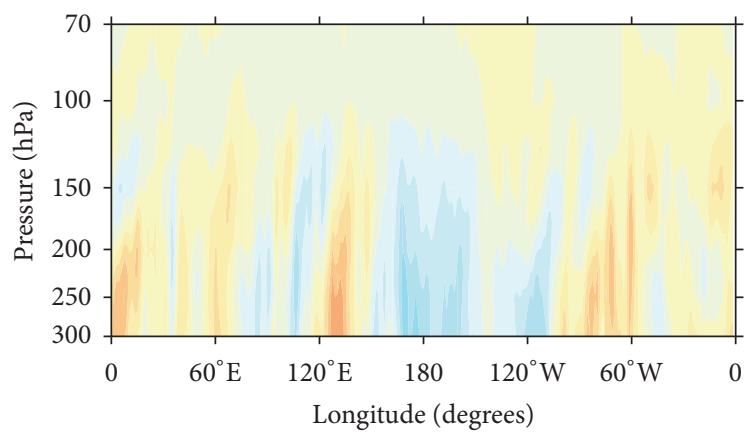

(c)

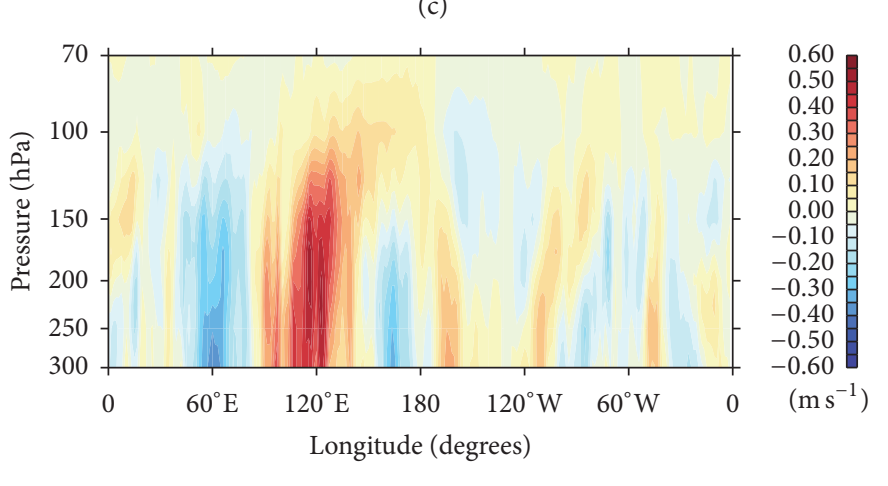

(e)
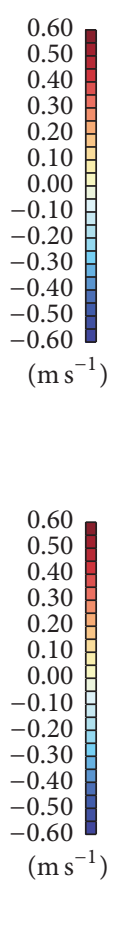

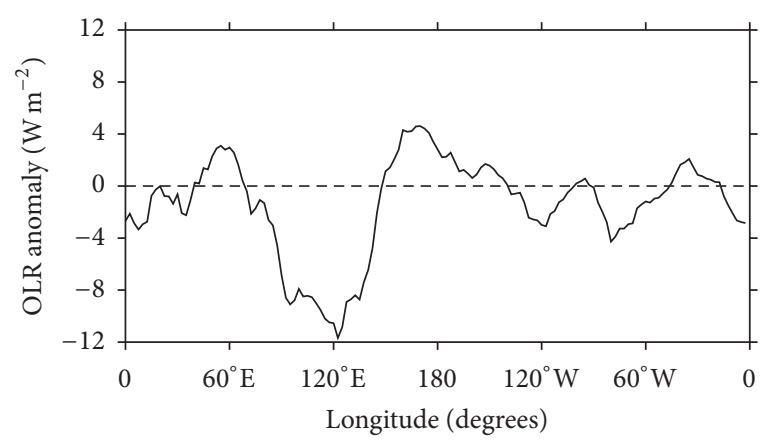

(b)

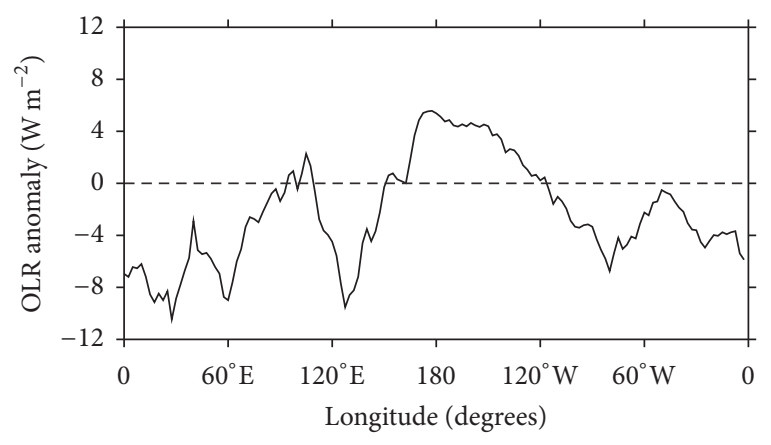

(d)

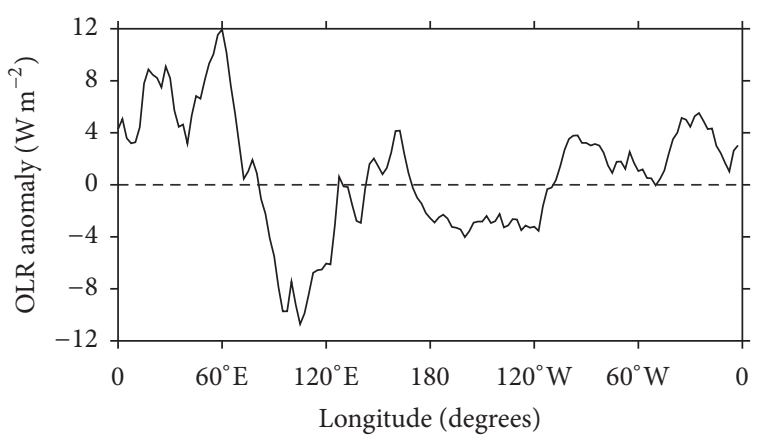

(f)

FIGURE 4: Longitude-pressure cross sections of tropical mean $\left(20^{\circ} \mathrm{N}-20^{\circ} \mathrm{S}\right)$ vertical velocity anomalies (a and c) and meridional distributions of tropical mean OLR anomalies (b and d) during the "prewarming" (a and b) and "postwarming" (c and d) periods in 1999. (e and f) Same as Figure 2(c) but for vertical velocity anomalies (e) and OLR anomalies (f), respectively.

confirmed the results of Zhang [51] and suggested that OLR drastically decreases increasing SST, when SST varies from $26.5^{\circ} \mathrm{C}$ to $29.5^{\circ} \mathrm{C}$. The mean SSTs over the tropical western Pacific Ocean during the "prewarming and postwarming" periods are $28.6^{\circ} \mathrm{C}$ and $27.9^{\circ} \mathrm{C}$, respectively. Hence, the SST warming pattern may be one of the main factors causing the enhanced deep convection during the "prewarming" period.

The zonal wind anomalies associated with the QBO could lead to anomalous meridional circulations [55, 56]. Anomalous westerly wind shear during the west phase of the QBO which descends from the upper stratosphere to the lower stratosphere induces an anomalous equatorward motion that leads to a warmer and lower tropopause in the tropics and vice versa for the east phase of the QBO [41]. Figure 6(a) shows the time series of CPTT variations and
$70 \mathrm{hPa}$ zonal wind anomalies averaged over the latitude bands $\left(10^{\circ} \mathrm{N}-10^{\circ} \mathrm{S}\right)$. It can be seen that the east phase of the QBO during the "prewarming" period converts to the west phase of the QBO during the "postwarming" period. The correlation coefficients between the CPTT and the zonal wind variations are significant during the "warming" period, indicating that the QBO may be responsible for the strong warming of the tropical tropopause in 1999. To further investigate the effect of the QBO on the tropopause, Figures 6(b) and 6(c) show time-pressure cross sections of tropical averaged zonal wind and temperature variations, respectively. From Figure 6(b), we can identify a transition from the east phase of the QBO during the "prewarming" period to the west phase of the QBO during the "postwarming" period at tropopause layer, which leads to a transition from negative temperature anomalies to 


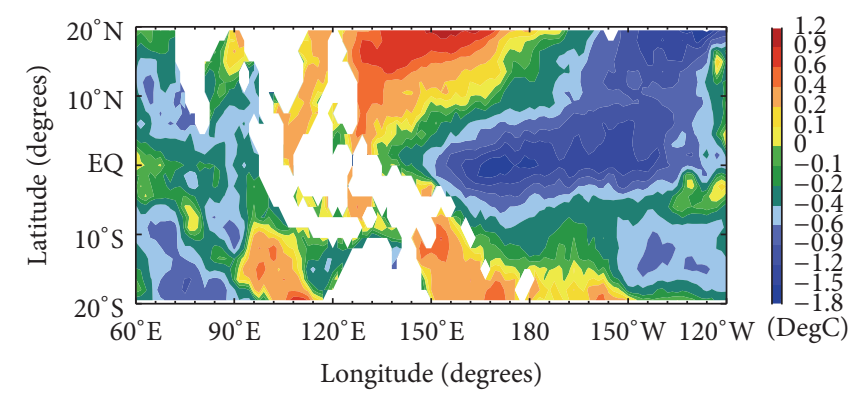

(a)

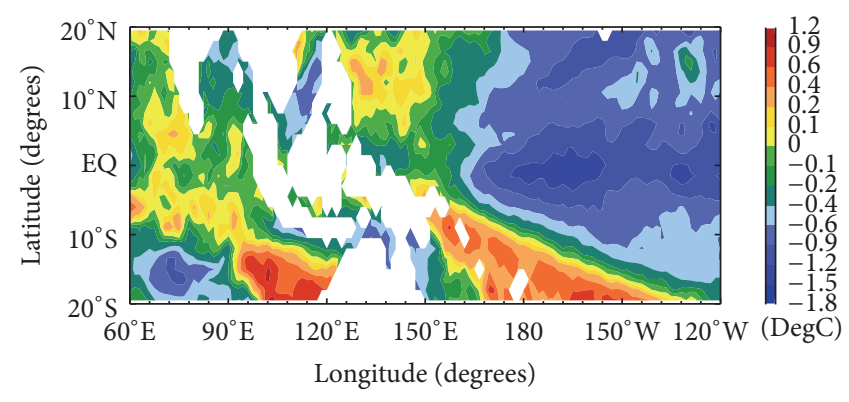

(b)

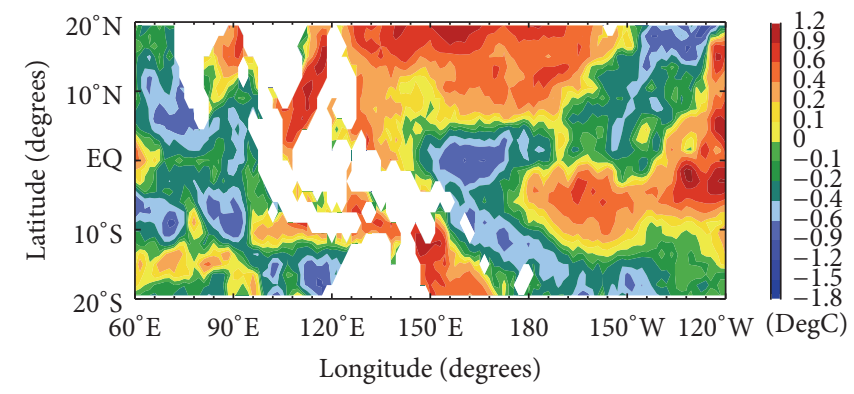

(c)

FIGURE 5: The spatial distributions of SSTs during the "prewarming" (a) and "postwarming" (b) periods. (c) Same as Figure 2(c) but for SST.

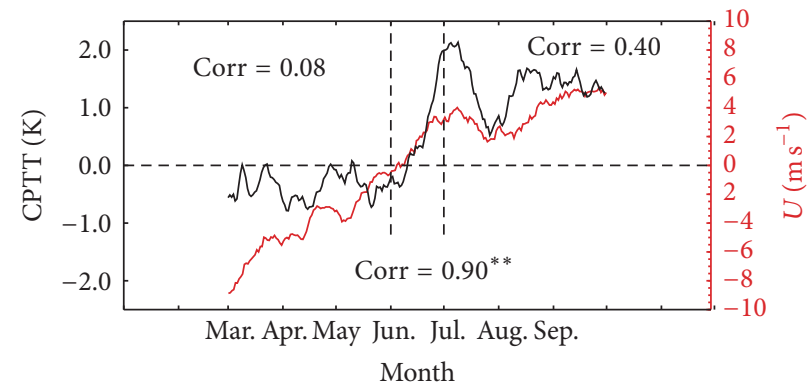

(a)

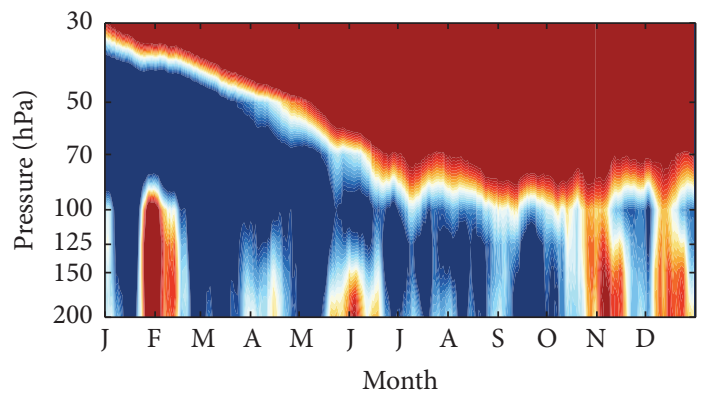

(b)

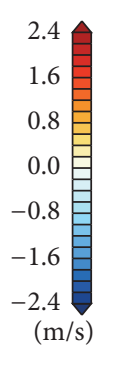$$
\text { }
$$

Figure 6: (a) Same as Figure 3(b) but for CPTT and $10^{\circ} \mathrm{N}-10^{\circ} \mathrm{S}$ averaged $70 \mathrm{hPa}$ zonal wind. Time-pressure cross sections of (b) zonal wind and (c) temperature daily anomalies in 1999. “**” denotes that the correlation coefficients exceed the significance test at the $95 \%$ confidence level.

positive temperature anomalies (Figure 6(c)). This process would represent a key influence on the warming of the tropopause. The QBO signal in the tropical tropopause is mainly characterized by zonally symmetric structure $[27,28]$, and the zonally symmetric pattern of CPTT anomalies shown in Figure 2(b) further confirms the effect of the QBO on CPTT.

Randel et al. [19] pointed out that the enhanced tropical upwelling associated with the BDC results in a colder tropical tropopause after 2001, indicating that the strength of the BDC 


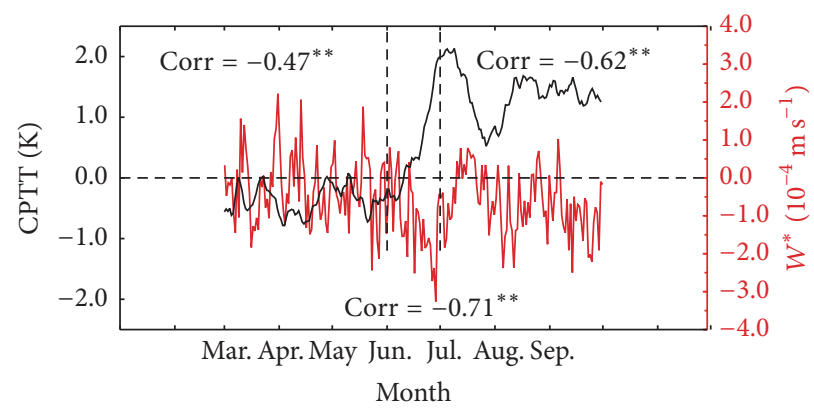

(a)

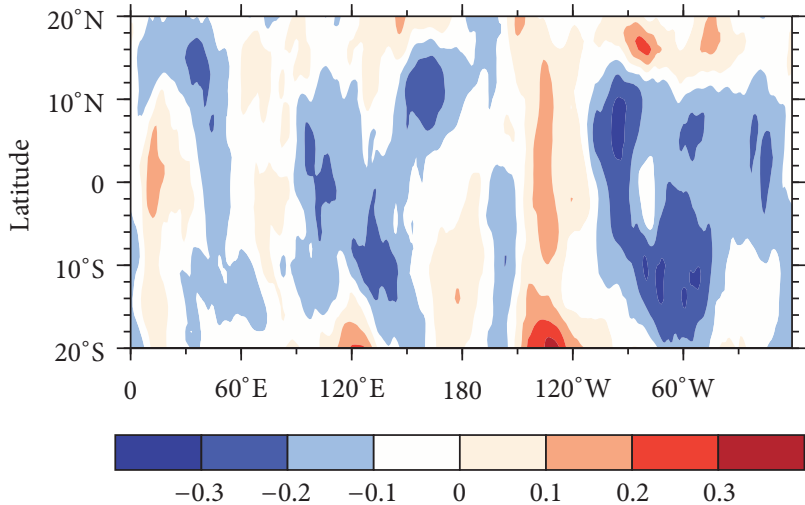

(b)

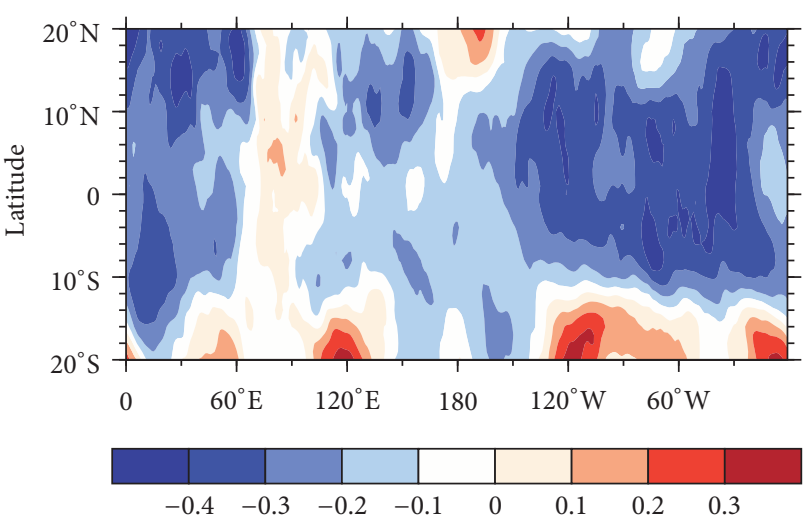

(c)

FIGURE 7: (a) Same as Figure 3(b) but for CPTT and $100 \mathrm{hPa}$ vertical velocity of the BDC. The maps of correlation coefficients between CPTT and $100 \mathrm{hPa}$ vertical velocity of the BDC over the tropical region during the "prewarming" (b) and "postwarming" (c) periods. “**” denotes that the correlation coefficients exceed the significance test at the $95 \%$ confidence level.

plays an important role in the variations of CPTT. Figure 7(a) shows the time series of CPTT and variations in the vertical velocity of the BDC over the tropical regions. It shows that the BDC is weakened during the "warming" period. During the "postwarming" period, the BDC is slightly strengthened compared with the period of "warming." During the "prewarming," "warming," and "postwarming" periods, the maximum correlation coefficients between the vertical velocity of the BDC and the CPTT can reach up to $-0.47,-0.72$, and -0.62 when the BDC leads the CPTT by 4 days, 3 days, and 13 days, respectively. The enhanced (weakened) tropical upwelling corresponds to cooler (warmer) CPTT. Figures 7 (b) and 7 (c) further show the map of correlation coefficients between the vertical velocity of the BDC and CPTT variations over the tropical regions during the "prewarming and postwarming" periods. The vertical velocity of the BDC is negatively correlated with the CPTT during these two periods. During the "prewarming" period, significant correlation coefficients are mostly located over the tropical eastern Pacific Ocean with the highest correlation coefficient being -0.34. During the "postwarming" period, significant correlation coefficients are found over the whole Pacific and Indian Oceans, especially over the tropical central and eastern Pacific, where the correlation coefficient can reach up to -0.4 .
Dhomse et al. [57] revealed that the strength of planetary wave activity in the stratosphere associated with the EliassenPalm flux (EP flux) is strongly correlated with the strength of the BDC. Figure 8 shows the patterns of the EP flux and the EP flux divergence during the "postwarming" period. Figures 8 (a) and 8(b) are the climatology and the anomaly distributions associated with the EP flux, respectively. During the "postwarming" period, tropospheric planetary waves enter stratosphere in the Southern Hemisphere middle latitudes (Figure 8(a)). The downward EP flux anomalies and positive EP flux divergence anomalies in the southern middle latitudes of the stratosphere indicate that the planetary wave activity is weakened during this period (Figure 8(b)). This weakening of planetary wave activity is responsible for the abatement of the BDC [58] during the "postwarming" period.

\section{The Contributions of Different Impact Factors to Tropopause Warming in 1999}

The analysis above suggests that deep convection, the QBO, and upwelling associated with the $\mathrm{BDC}$ all contribute to the strong warming of the tropical tropopause in 1999. A multiple regression model (MLR) analysis is used to calculate 


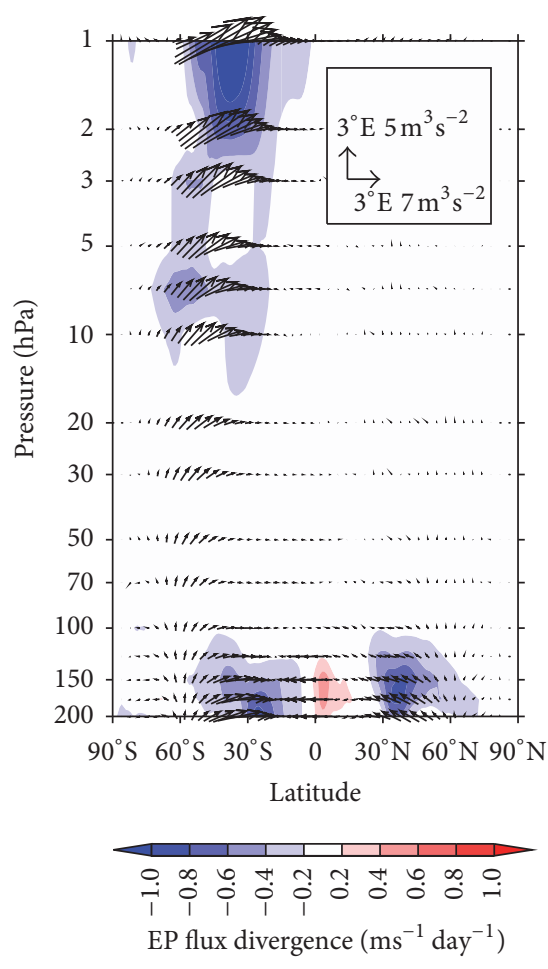

(a)

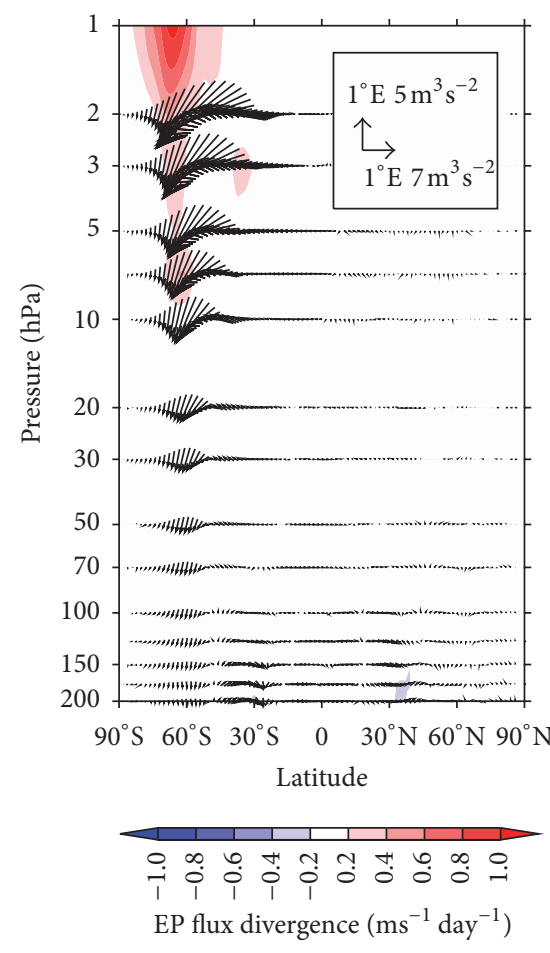

(b)

FIGURE 8: (a) Climatological EP flux for the period between 1994 and 2005 and (b) anomalous EP flux during the "postwarming" period. Colors indicate EP flux divergence.

TABLE 1: The correlation coefficients among olr, $u$, and $w_{s}$ used in regression model during three periods. The number in the bracket represents the effective number $\left(N^{\text {eff }}\right)$ of DOF.

\begin{tabular}{lccc}
\hline$R$ & Prewarming & Warming & Postwarming \\
\hline olr \& $u$ & $0.27(9)$ & $0.79(4)$ & $0.36(19)$ \\
$u \& w_{s}$ & $-0.11(100)$ & $-0.55(8)$ & $-0.25(26)$ \\
olr \& $w_{s}$ & $-0.11(88)$ & $-0.49(11)$ & $-0.05(37)$ \\
\hline
\end{tabular}

the variance contributions of these factors to the variations in the CPTT. Note that the MLR analysis has been widely used to study the attribution of the observed variations [59]. The proxy variables applied here are OLR over the tropical western Pacific Ocean (olr), zonal mean wind at $70 \mathrm{hPa}$ averaged over $10^{\circ} \mathrm{N}-10^{\circ} \mathrm{S}(u)$, and tropical upwelling velocity at $100 \mathrm{hPa}$ averaged over $20^{\circ} \mathrm{N}-20^{\circ} \mathrm{S}\left(w_{s}\right)$. The MLR equation is as follows:

$$
\operatorname{cptt}(t)=b_{0}+b_{1} \mathrm{olr}+b_{2} u+b_{3} w_{s}
$$

where $t$ is the day and $b_{i}$ is the regression coefficient associated with each factor.

Before establishing the regression model, it is necessary to investigate the correlation among these three regressors to check whether these three regressors are independent of each other. Table 1 lists the correlation coefficients among olr, $u$, and $w_{s}$ used in the MLR analysis during three periods ("prewarming," "warming," and "postwarming"). It shows

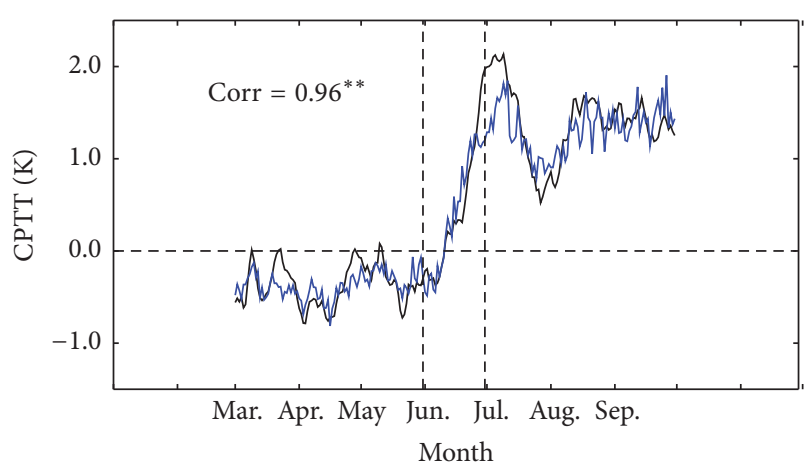

FIGURE 9: Regressed (blue line) and observed (black line) CPTT daily time series. For details on the regression, please see Section 4. "Corr" represents the correlation coefficient between observed and regressed CPTTs for 1999. “**” denotes that the correlation coefficients exceed the significance test at the $95 \%$ confidence level.

that the deep convection, $\mathrm{QBO}$, and $\mathrm{BDC}$ are uncorrelated at the $95 \%$ confidence level for each period. It implies that the three regressors are independent of each other.

Figure 9 shows the regressed and observed daily mean time series of CPTT variations in 1999. The high correlation coefficient $(r=0.96)$ between the regressed and observed CPTT variations indicates that the variations of deep convection, the QBO, and the upwelling associated with the BDC can explain the CPTT in 1999 well. 
TABLE 2: Explained variances of deep convection, the QBO, and upwelling associated with the BDC during three periods in the regression model.

\begin{tabular}{lccc}
\hline & Prewarming & Warming & Postwarming \\
\hline Deep convection & $22 \%{ }^{*}$ & $1 \%$ & $4 \%^{*}$ \\
QBO & $0.7 \%$ & $52 \%{ }^{*}$ & $6 \%{ }^{*}$ \\
Upwelling & $17 \%{ }^{*}$ & $3 \%$ & $28 \%^{*}$ \\
\hline
\end{tabular}

" $*$ " denotes that the explained variances exceed the significance test at the $99 \%$ confidence level.

The explained variances of the three factors during three ("prewarming," "warming," and "postwarming") periods are listed in Table 2. We can see that the explained variances of the three factors are different during the three periods and the maximum variance contributor for each period is also different. During the "prewarming" period, deep convection and the BDC can account for $22 \%$ and $17 \%$ of explained variances of the CPTT variations, respectively. This implies that the enhanced deep convection and upwelling associated with the BDC contribute to the colder tropopause to a large extent. During the period of "warming," QBO explains $52 \%$ of the variance, indicating that east-west QBO phase transition largely contributes to the large warming rate of the CPTT in June 1999. During the "postwarming" period, the BDC contributes to $28 \%$ of the explained variance. This implies that the anomalous warming of the tropopause after a strong rate of increase in the CPTT in June 1999 is most likely attributed to the reduction of the BDC. The MLR analysis shows that $\mathrm{QBO}$ east-west phase transition is largely responsible for the large rate of increase in the CPTT in June 1999. One may wonder that QBO east-west phase transition is a regular phenomenon with $\sim 2$-year cycle; why does the CPTT show large rate of increase only in 1999? Figure 10 shows time-pressure cross sections of temperature and zonal wind from 1994 to 2005. There are evident QBO signals in both tropical zonal wind and temperature. To be specific, westerly shear in the zonal wind is associated with warm temperature anomalies and easterly shear is associated with cold anomalies. In the years 1995, 1997, 1999, 2002, and 2004 , westerly winds gradually propagate downward from the upper stratosphere to the lower stratosphere with the eastwest phase transition of the $\mathrm{QBO}$ at $70 \mathrm{hPa}$. Correspondingly, a warm anomaly propagates from the upper stratosphere to the lower stratosphere in these years. It is interesting that the warm temperature anomaly only descends to $70 \mathrm{hPa}$ in $1995,1997,1999,2002$, and 2004, while the warm temperature anomaly in $1999 \mathrm{can}$ reach the tropopause. This indicates that the downward propagation of the QBO signal from the upper stratosphere to the tropopause plays a critical role in the large rate of increase in the CPTT in 1999.

\section{Conclusions}

Using reanalysis datasets, the warming of the tropical tropopause (the relatively large increase in CPTT) in 1999 and its evolution are investigated. It is found that there is a strong rate of increase in the CPTT in June 1999 during the

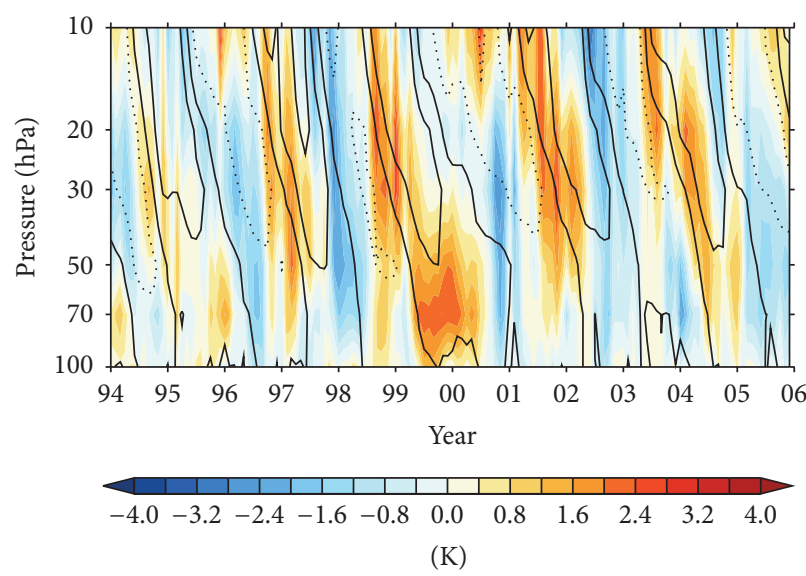

FIGURE 10: Time-pressure cross sections of temperature (colors) and zonal wind (contour levels) anomalies from 1994 to 2005. The contour interval of zonal wind is $10 \mathrm{~m} / \mathrm{s}$, and the value range is from $-40 \mathrm{~m} / \mathrm{s}$ to $40 \mathrm{~m} / \mathrm{s}$. The temperature anomalies are calculated here by removing the seasonal cycle. The zonal anomalies are calculated here by removing the time averaged zonal wind from 1994 to 2005.

period of "warming." Negative CPTT anomalies occur before June (March-April-May) during the "prewarming" period, and large positive anomalies occur after June (July-AugustSeptember) during the "postwarming" period. It is further revealed that the variations of CPTT are closely related to deep convection, the $\mathrm{QBO}$, and the tropical upwelling associated with the BDC. During the "prewarming" period, enhanced deep convection induced by an increase in SST over the western Pacific together with enhanced tropical upwelling of the BDC contributes to a higher and colder tropopause. The MLR analysis shows that the changes in deep convection and the tropical upwelling account for $22 \%$ and $17 \%$ of explained variances of the CPTT variations, respectively. During the period of "warming," the QBO evidently undergoes a transition from its east phase to its west phase. MLR analysis shows that this east-west phase transition in the $\mathrm{QBO}$ can contribute up to $50 \%$ of the explained variance in the large rate of increase in tropopause warming. During the "postwarming" period, weakening of the mean tropical upwelling of the BDC resulting from reduced wave activity in the southern middle latitudes of the stratosphere results in a warmer tropical tropopause that explains $28 \%$ of the variance in CPTT.

\section{Conflicts of Interest}

The authors declare that they have no conflicts of interest.

\section{Acknowledgments}

Funding for this project was provided by the Science Foundations of China (41575039 and 41575038), the 973 Project of China (2014CB441202), and the Youth Scholars Program of Beijing Normal University. The authors acknowledge the datasets from the ERA-Interim, MERRA, and NCEP-CFRS. 


\section{References}

[1] M. P. Baldwin and T. J. Dunkerton, "Stratospheric harbingers of anomalous weather regimes," Science, vol. 294, no. 5542, pp. 581-584, 2001.

[2] J. Zhang, W. Tian, M. P. Chipperfield, F. Xie, and J. Huang, "Persistent shift of the Arctic polar vortex towards the Eurasian continent in recent decades," Nature Climate Change, vol. 6, no. 12, pp. 1094-1099, 2016.

[3] F. Xie, J. Li, W. Tian et al., "A connection from Arctic stratospheric ozone to El Niño-Southern oscillation," Environmental Research Letters, vol. 11, no. 12, Article ID 124026, 2016.

[4] D. Guo, Y. Su, C. Shi, J. Xu, and A. M. Powell, "Double core of ozone valley over the Tibetan Plateau and its possible mechanisms," Journal of Atmospheric and Solar-Terrestrial Physics, vol. 130, no. 8, pp. 127-131, 2015.

[5] D. Guo, P. Wang, X. Zhou, Y. Liu, and W. Li, "Dynamic effects of the South Asian high on the ozone valley over the Tibetan Plateau," Acta Meteorologica Sinica, vol. 26, no. 2, pp. 216-228, 2012.

[6] W. Tian and M. P. Chipperfield, "A new coupled chemistryclimate model for the stratosphere: the importance of coupling for future $\mathrm{O}_{3}$-climate predictions," Quarterly Journal of the Royal Meteorological Society, vol. 131, no. 605, pp. 281-303, 2005.

[7] G. Myhre, J. S. Nilsen, L. Gulstad, K. P. Shine, B. Rognerud, and I. S. A. Isaksen, "Radiative forcing due to stratospheric water vapour from CH4 oxidation," Geophysical Research Letters, vol. 34, no. 1, Article ID L01807, 2007.

[8] P. M. D. F. Forster and K. P. Shine, "Assessing the climate impact of trends in stratospheric water vapor," Geophysical Research Letters, vol. 29, no. 6, pp. 10-1-10-4, 2002.

[9] A. E. Dessler, M. R. Schoeberl, T. Wang, S. M. Davis, and K. H. Rosenlof, "Stratospheric water vapor feedback," Proceedings of the National Academy of Sciences of the United States of America, vol. 110, no. 45, pp. 18087-18091, 2013.

[10] A. J. Simmons, A. Untch, C. Jakob, P. Kållberg, and P. Undén, "Stratospheric water vapour and tropical tropopause temperatures in ECMWF analyses and multi-year simulations," Quarterly Journal of the Royal Meteorological Society, vol. 125, no. 553, pp. 353-386, 1999.

[11] S. Fueglistaler, M. Bonazzola, P. H. Haynes, and T. Peter, "Stratospheric water vapor predicted from the Lagrangian temperature history of air entering the stratosphere in the tropics," Journal of Geophysical Research D: Atmospheres, vol. 110, no. 8, Article ID D08107, 2005.

[12] K. H. Rosenlof and G. C. Reid, "Trends in the temperature and water vapor content of the tropical lower stratosphere: sea surface connection," Journal of Geophysical Research: Atmospheres, vol. 113, no. 6, Article ID D06107, 2008.

[13] A. Gettelman, M. I. Hegglin, S.-W. Son et al., "Multi-model assessment of the upper troposphere and lower stratosphere: tropics and trends," Journal of Geophysical Research Atmosphere, vol. 115, Article ID D00M08, 2010.

[14] T. Wang, A. E. Dessler, M. R. Schoeberl, W. J. Randel, and J.-E. Kim, "The impact of temperature vertical structure on trajectory modeling of stratospheric water vapor," Atmospheric Chemistry and Physics, vol. 15, no. 6, pp. 3517-3526, 2015.

[15] A. E. Dessler, H. Ye, T. Wang et al., "Transport of ice into the stratosphere and the humidification of the stratosphere over the 21st century," Geophysical Research Letters, vol. 43, no. 5, pp. 2323-2329, 2016.
[16] A. W. Brewer, "Evidence for a world circulation provided by the measurements of helium and water vapour distribution in the stratosphere," Quarterly Journal of the Royal Meteorological Society, vol. 75, no. 326, pp. 351-363, 1949.

[17] W. J. Randel, F. Wu, S. J. Oltmans, K. Rosenlof, and G. E. Nedoluha, "Interannual changes of stratospheric water vapor and correlations with tropical tropopause temperatures," Journal of the Atmospheric Sciences, vol. 61, no. 17, pp. 2133-2148, 2004.

[18] A. E. Dessler, M. R. Schoeberl, T. Wang, S. M. Davis, K. H. Rosenlof, and J.-P. Vernier, "Variations of stratospheric water vapor over the past three decades," Journal of Geophysical Research Atmospheres, vol. 119, no. 22, pp. 12588-12598, 2014.

[19] W. J. Randel, F. Wu, H. Vömel, G. E. Nedoluha, and P. Forster, "Decreases in stratospheric water vapor after 2001: links to changes in the tropical tropopause and the Brewer-Dobson circulation," Journal of Geophysical Research: Atmospheres, vol. 111, no. 12, Article ID D12312, 2006.

[20] W. Tian and M. P. Chipperfield, "Stratospheric water vapor trends in a coupled chemistry-climate model," Geophysical Research Letters, vol. 33, no. 6, Article ID L06819, 2006.

[21] G. C. Reid and K. S. Gage, "The tropical tropopause over the western Pacific: wave driving, convection, and the annual cycle," Journal of Geophysical Research Atmospheres, vol. 101, no. 16, pp. 21233-21241, 1996.

[22] E. J. Jensen, O. B. Toon, H. B. Selkirk, J. D. Spinhirne, and M. R. Schoeberl, "On the formation and persistence of subvisible cirrus clouds near the tropical tropopause," Journal of Geophysical Research Atmospheres, vol. 101, no. 16, pp. 21361-21375, 1996.

[23] S. Massie, A. Gettelman, W. Randel, and D. Baumgardner, "Distribution of tropical cirrus in relation to convection," Journal of Geophysical Research Atmospheres, vol. 107, no. 21, pp. AAC 19-1-AAC 19-16, 2002.

[24] A. Gettelman, T. Birner, V. Eyring et al., "The tropical tropopause layer 1960-2100," Atmospheric Chemistry \& Physics Discussions, vol. 9, pp. 1621-1637, 2009.

[25] S.-W. Son, L. M. Polvani, D. W. Waugh et al., "The impact of stratospheric ozone recovery on tropopause height trends," Journal of Climate, vol. 22, no. 2, pp. 429-445, 2009.

[26] S. Feng, Y. Fu, and Q. Xiao, "Trends in the global tropopause thickness revealed by radiosondes," Geophysical Research Letters, vol. 39, no. 20, Article ID L20706, 2012.

[27] X. L. Zhou, M. A. Geller, and M. Zhang, "Cooling trend of the tropical cold point tropopause temperatures and its implications," Journal of Geophysical Research: Atmospheres, vol. 106, no. 2, pp. 1511-1522, 2001.

[28] W. J. Randel, F. Wu, and D. J. Gaffen, "Interannual variability of the tropical tropopause derived from radiosonde data and NCEP reanalyses," Journal of Geophysical Research: Atmospheres, vol. 105, no. 12, pp. 15509-15523, 2000.

[29] A. Gettelman and P. M. D. F. Forster, "A climatology of the tropical tropopause layer," Journal of the Meteorological Society of Japan, vol. 80, no. 4, pp. 911-924, 2002.

[30] H. Hatsushika and K. Yamazaki, "Interannual variations of temperature and vertical motion at the tropical tropopause associated with ENSO," Geophysical Research Letters, vol. 28, no. 15, pp. 2891-2894, 2001.

[31] J. Kim and S.-W. Son, "Tropical cold-point tropopause: climatology, seasonal cycle, and intraseasonal variability derived from COSMIC GPS radio occultation measurements," Journal of Climate, vol. 25, no. 15, pp. 5343-5360, 2012. 
[32] S.-W. Son, Y. Lim, C. Yoo, H. H. Hendon, and J. Kim, "Stratospheric control of the madden-julian oscillation," Journal of Climate, vol. 30, no. 6, pp. 1909-1922, 2017.

[33] E. J. Highwood and B. J. Hoskins, "The tropical tropopause," Quarterly Journal of the Royal Meteorological Society, vol. 124, no. 549, pp. 1579-1604, 1998.

[34] S. Fueglistaler, A. E. Dessler, T. J. Dunkerton, I. Folkins, Q. Fu, and P. W. Mote, "Tropical tropopause layer," Reviews of Geophysics, vol. 47, no. 1, pp. 227-231, 2009.

[35] X. L. Zhou, M. A. Geller, and M. Zhang, "Tropical cold point tropopause characteristics derived from ECMWF reanalyses and soundings," Journal of Climate, vol. 14, no. 8, pp. 1823-1838, 2001.

[36] F. Xie, J. Li, W. Tian, Y. Li, and J. Feng, "Indo-pacific warm pool area expansion, modoki activity, and tropical cold-point tropopause temperature variations," Scientific Reports, vol. 4, no. 13, article 4552, 2014.

[37] Q. Fu, P. Lin, S. Solomon, and D. L. Hartmann, "Observational evidence of strengthening of the Brewer-Dobson circulation since 1980," Journal of Geophysical Research: Atmospheres, vol. 120, no. 19, pp. 10214-10228, 2015.

[38] J. S. Wang, D. J. Seidel, and M. Free, "How well do we know recent climate trends at the tropical tropopause?" Journal of Geophysical Research Atmospheres, vol. 117, no. 9, Article ID D09118, 2012.

[39] F. Xie, J. Li, W. Tian, and J. Feng, "Signals of El Niño Modoki in the tropical tropopause layer and stratosphere," Atmospheric Chemistry \& Physics, vol. 12, no. 11, pp. 5259-5273, 2012.

[40] D. Hu, W. Tian, Z. Guan, Y. Guo, and S. Dhomse, "Longitudinal asymmetric trends of tropical cold-point tropopause temperature and their link to strengthened walker circulation," Journal of Climate, vol. 29, no. 21, pp. 7755-7771, 2016.

[41] C. C. Collimore, D. W. Martin, M. H. Hitchman, A. Huesmann, and D. E. Waliser, "On the relationship between the QBO and tropical deep convection," Journal of Climate, vol. 16, no. 15, pp. 2552-2568, 2003.

[42] D. G. Andrews, J. R. Holton, and C. B. Leovy, Middle Atmosphere Dynamics, Academic Press, 1987.

[43] C. S. Bretherton, M. Widmann, V. P. Dymnikov, J. M. Wallace, and I. Bladé, "The effective number of spatial degrees of freedom of a time-varying field," Journal of Climate, vol. 12, no. 7, pp. 1990-2009, 1999.

[44] Y. Li, J. Li, and J. Feng, "A teleconnection between the reduction of rainfall in southwest Western Australia and north China," Journal of Climate, vol. 25, no. 24, pp. 8444-8461, 2012.

[45] A. Simmons, S. Uppala, and D. P. Dee, "Update on ERAinterim," ECMWF Newsletter, vol. 111, no. 5, 2007.

[46] A. J. Simmons, S. M. Uppala, D. P. Dee, and S. Kobayashi, "ERAinterim: new ECMWF reanalysis products from 1989 onwards," ECMWF Newsletter, vol. 110, no. 110, pp. 25-35, 2007.

[47] D. P. Dee, S. M. Uppala, A. J. Simmons et al., “The ERA-Interim reanalysis: configuration and performance of the data assimilation system," Quarterly Journal of the Royal Meteorological Society, vol. 137, no. 656, pp. 553-597, 2011.

[48] E. Nishimoto and M. Shiotani, "Seasonal and interannual variability in the temperature structure around the tropical tropopause and its relationship with convective activities," Journal of Geophysical Research Atmospheres, vol. 117, no. 2, Article ID D02104, 2012.

[49] W. Wang, K. Matthes, T. Schmidt, and L. Neef, "Recent variability of the tropical tropopause inversion layer," Geophysical Research Letters, vol. 40, no. 23, pp. 6308-6313, 2013.
[50] A. Gettelman, M. L. Salby, and F. Sassi, "Distribution and influence of convection in the tropical tropopause region," Journal of Geophysical Research D: Atmospheres, vol. 107, no. 910, pp. ACL 6-1-ACL 6-12, 2002.

[51] C. Zhang, "Large-scale variability of atmospheric deep convection in relation to sea surface temperature in the tropics," Journal of Climate, vol. 6, no. 10, pp. 1898-1913, 1993.

[52] T. Matsuno, "Quasi-geostrophic motions in the Equatorial area," Journal of the Meteorological Society of Japan, vol. 44, no. 1, pp. 25-42, 1966.

[53] A. E. Gill, "Some simple solutions for heat-induced tropical circulation," Quarterly Journal of the Royal Meteorological Society, vol. 106, no. 449, pp. 447-462, 1980.

[54] K.-M. Lau, H.-T. Wu, and S. Bony, "The role of large-scale atmospheric circulation in the relationship between tropical convection and sea surface temperature," Journal of Climate, vol. 10, no. 3, pp. 381-392, 1997.

[55] R. A. Plumb and R. C. Bell, "A model of the quasi-biennial oscillation on an equatorial beta-plane," Quarterly Journal of the Royal Meteorological Society, vol. 108, no. 456, pp. 335-352, 1982.

[56] A. S. Huesmann and M. H. Hitchman, "The stratospheric quasibiennial oscillation in the NCEP reanalyses: climatological structures," Journal of Geophysical Research Atmospheres, vol. 106, no. 11, pp. 11859-11874, 2001.

[57] S. Dhomse, M. Weber, and J. Burrows, "The relationship between tropospheric wave forcing and tropical lower stratospheric water vapor," Atmospheric Chemistry \& Physics, vol. 8, no. 3, pp. 471-480, 2008.

[58] P. A. Newman, E. R. Nash, and J. E. Rosenfield, "What controls the temperature of the Arctic stratosphere during the spring?" Journal of Geophysical Research Atmospheres, vol. 106, no. 17, pp. 19999-20010, 2001.

[59] J. Zhang, W. Tian, F. Xie et al., "Climate warming and decreasing total column ozone over the Tibetan Plateau during winter and spring," Tellus, Series B: Chemical and Physical Meteorology, vol. 66, no. 1, Article ID 23415, 2014. 

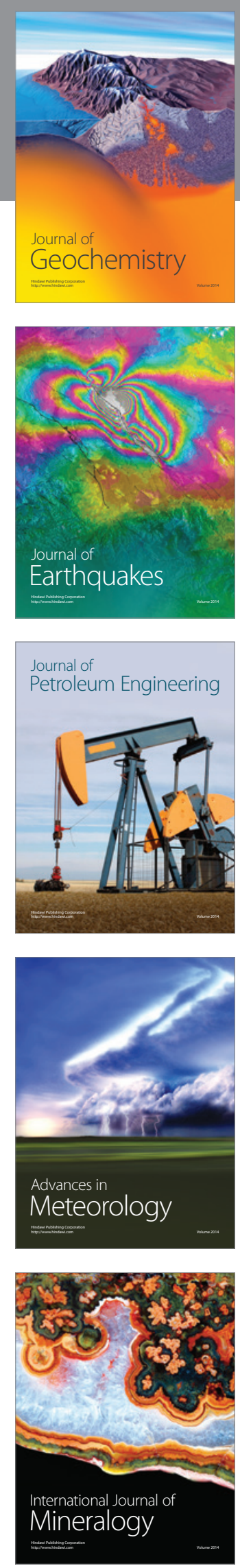
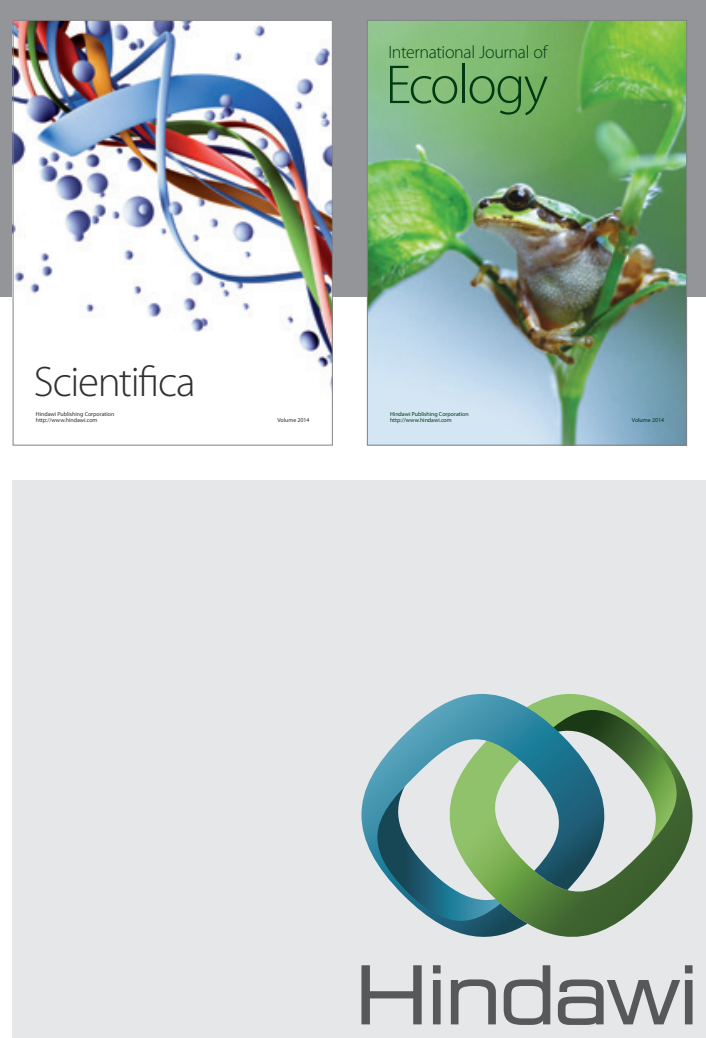

Submit your manuscripts at

https://www.hindawi.com
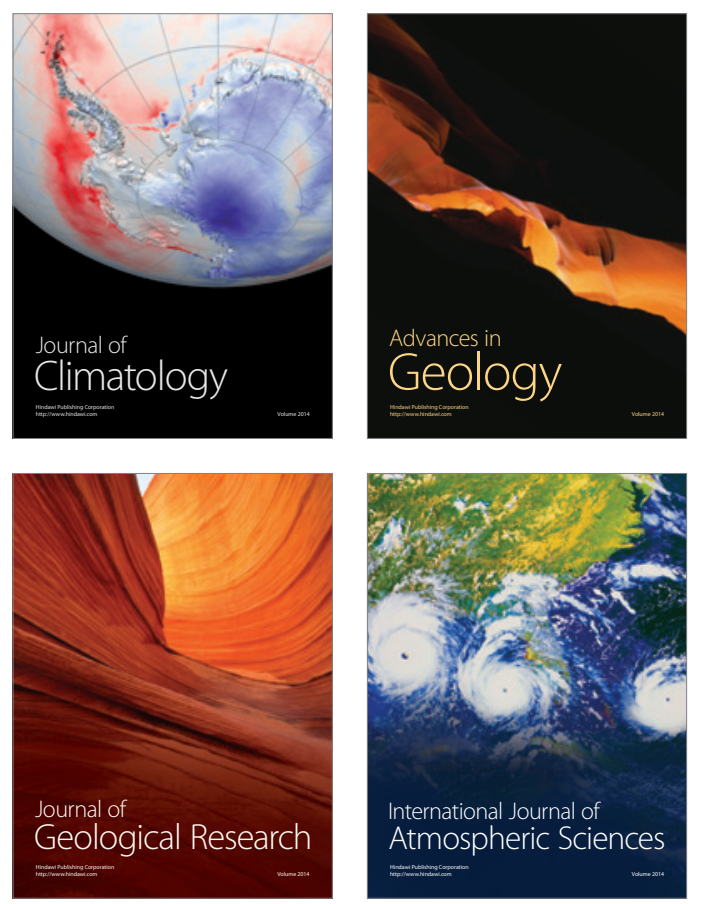

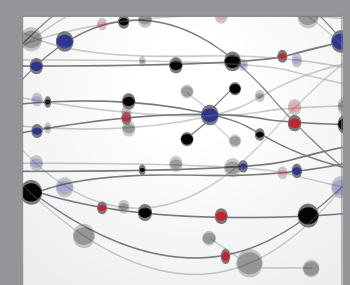

The Scientific

\section{World Journal}
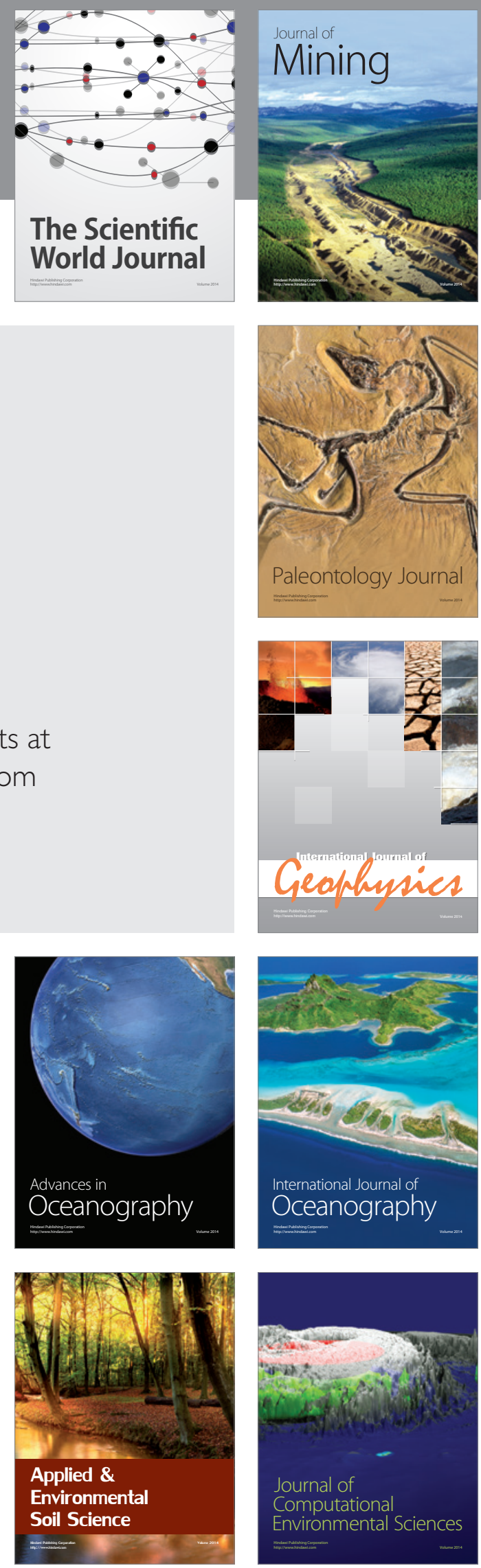